\title{
Forma recessiva da síndrome de Freeman-Sheldon - relato de dois irmãos afetados
}

\author{
Recessive type of Freeman-Sheldon syndrome - Report of two affected siblings
}

\author{
Gerson Carakushansky ${ }^{1}$, Isaías S. Paiva ${ }^{2}$, Evelyn Kahn ${ }^{3}$, Márcia G. Ribeiro ${ }^{4}$
}

\section{Resumo}

Objetivo: contribuir para a divulgação das peculiaridades da síndrome de Freeman-Sheldon e, em particular, do alto risco de recorrência em irmãos na sua forma recessiva, valorizando a importância do aconselhamento genético das famílias após o nascimento de uma criança afetada.

Descrição: os autores descrevem e comentam dois casos pediátricos da síndrome de Freeman-Sheldon em irmãos cujos progenitores são normais. Os casos relatados têm suas peculiaridades mais significativas confrontadas com achados da literatura médica obtida através de pesquisa bibliográfica sobre o tema. Os casos aqui descritos corroboram ainda mais a existência de uma forma recessiva da síndrome de Freeman-Sheldon. Apesar de alguns autores sugerirem uma maior frequiência de um comprometimento neurológico grave nesta forma da síndrome, nos dois casos aqui apresentados estas manifestações não eram aparentes.

Comentários: a síndrome de Freeman-Sheldon é heterogênea não só na sua apresentação clínica como também na sua transmissão genética. É muito importante conhecer a existência de mais de uma forma de transmissão hereditária desta síndrome, para que, após o nascimento de uma criança afetada, possa ser oferecido à família um aconselhamento genético que leve em consideração as várias possibilidades. Nestes casos estaria justificada a utilização de riscos empíricos de recorrência.

J Pediatr (Rio J) 2001; 77 (5): 425-30: síndrome de FreemanSheldon, displasia cranio-carpo-tarsal, artrogripose, aconselhamento genético.

\section{Introdução}

A displasia cranio-carpo-tarsal, descrita pela primeira vez por Freeman e Sheldon em $1938^{1}$ é uma síndrome morfologicamente bem caracterizada, constituindo um

1. Prof. Titular, Depto. Pediatria, Faculdade de Medicina UFRJ; Chefe do Serviço Genética IPPMG da UFRJ; Presidente Depto. Genética SBP.

2. Médico Estagiário do Serviço de Genética do IPPMG da UFRJ.

3. Prof ${ }^{a}$ Adjunta do Depto. de Pediatria da Faculdade de Medicina da UFRJ; Serviço de Genética do IPPMG da UFRJ.

4. Prof ${ }^{\mathrm{a}}$ Assistente do Depto. de Pediatria da Faculdade de Medicina da UFRJ; Serviço de Genética do IPPMG da UFRJ.

\begin{abstract}
Objective: to share knowledge and information about the peculiarities of the Freeman-Sheldon syndrome, especially concerning the high risk of recurrence of its recessive type in siblings, and to stress the importance of genetic counseling for families after the birth of an affected child.

Description: the authors describe and comment two pediatric cases of the Freeman-Sheldon syndrome in siblings born to healthy parents. These two cases present significant peculiarities that contradict the findings of the medical literature, obtained through bibliographic research about the subject. The cases described here corroborate the existence of a recessive type of the Freeman-Sheldon syndrome. In spite of the fact that some authors suggest a high frequency of severe neurological impairment in this type of syndrome, the two cases we analyzed did not show any apparent manifestation of such sequelae.

Comments: the Freeman-Sheldon syndrome is heterogeneous not only in its clinical presentation but also in its genetic transmission. It is very important to be informed about the existence of more than one form of hereditary transmission of this syndrome, since genetic counseling should take into consideration all possibilities. In these cases, the use of empiric risks of recurrence would be justified.
\end{abstract}

J Pediatr (Rio J) 2001; 77 (5): 425-30: Freeman-Sheldon syndrome, cranio-carpo-tarsal dysplasia, arthrogryposis, genetic counseling.

quadro dismórfico que associa alterações ósseas e contraturas articulares com uma expressão facial típica. Em homenagem a estes dois autores, ela ficou também conhecida como síndrome de Freeman-Sheldon (SFS). Ela faz parte das patologias que foram agrupadas dentro do grupo nosológico que atualmente conhecemos como distúrbios contraturais distais múltiplos congênitos ${ }^{2}$.

Inicialmente pensou-se que a síndrome era muito rara, mas até 1990 já existiam mais de 65 casos relatados na literatura $^{3}$. Ambos os sexos são afetados igualmente. A 
inteligência é usualmente normal, embora uma associação com retardo mental tenha sido ocasionalmente relatada, principalmente naqueles casos que se acompanham de anomalias estruturais importantes do sistema nervoso central.

As principais anormalidades ósseas das extremidades encontradas na SFS são a camptodactilia com desvio cubital das mãos e pé torto congênito combinando eqüinismo com varismo. As características faciais tipicamente incluem olhos introjetados com telecanto primário, bochechas permanentemente insufladas com projeção dos lábios para fora (posição de assobio), filtro alongado, cartilagem nasal pouco desenvolvida com narinas estreitadas e uma microstomia acompanhada de microglossia. A face é achatada, mantendo uma expressão fisionômica pouco variável, como se fosse uma máscara. Geralmente existe uma fosseta em forma de $\mathrm{H}$ na pele que recobre a região mentoniana.

A maioria dos casos relatados de SFS ocorre de forma esporádica, sem nenhuma história familiar, mas em várias famílias existe um típico padrão de herança autossômica dominante $^{4,5}$. Temtany e McKusick ${ }^{6}$ observaram a ocorrência desta síndrome em duas gerações em três diferentes famílias. Entretanto, surgiram algumas famílias relatadas na literatura, nas quais a síndrome exibe um padrão de herança que segue o modelo autossômico recessivo, ou seja, os progenitores são clinicamente normais, porém seriam possíveis portadores (heterozigotos) do gene responsável pela síndrome $e^{7-11}$. Podemos então afirmar que a SFS pode ser considerada uma entidade heterogênea na sua transmissão genética e/ou na sua apresentação clínica, tornando, portanto, o aconselhamento genético que deve ser oferecido aos progenitores, após o nascimento de uma criança afetada, um verdadeiro desafio.

O objetivo deste trabalho é o de relatar os casos de dois irmãos afetados pela SFS na sua forma autossômica recessiva, salientando a importância preventiva do aconselhamento genético, já que estas famílias estarão expostas a um alto risco de recorrência da síndrome na sua prole.

\section{Relato dos Casos}

\section{Caso 1}

T.A.M.C., branca, do sexo feminino, foi referida ao Serviço de Genética do IPPMG da UFRJ aos 23 meses de idade. Tratava-se do produto de uma segunda gestação não planejada e não desejada, mas com assistência pré-natal completa e sem intercorrências. Progenitora com 33 anos, gesta III, para III. Movimentos fetais foram notados a partir do $3^{0}$ mês da gestação. Não há história conhecida de exposição materna a medicamentos ou radiação. Nasceu a termo, de parto instrumental (fórceps) devido a um período expulsivo prolongado. Apresentação cefálica. Hidramnios normais. Choro fraco ao nascer. Nasceu cianótica segundo a mãe, mas ela desconhece a nota atribuída na avaliação pelo Apgar. $\mathrm{PN}=2.910 \mathrm{~g}$. Estatura ao nascer $=47 \mathrm{~cm}$. Não apresentou intercorrências perinatais. Obteve alta da maternidade juntamente com a mãe.

A paciente tem uma irmã com 4 anos de idade, aparentemente normal e um irmão (caso 2) com 5 meses de idade, o qual apresenta características fenotípicas semelhantes. Não há referência a doenças prévias. Um pouco após o nascimento de T.A.M.C., a mãe procurou um serviço de Genética Clínica onde, segundo ela, lhe foi informado que a sua filha tinha uma síndrome, mas que esta não teria grande repercussão no seu desenvolvimento cognitivo, sendo que o risco de vir a ter outra criança com o mesmo problema em uma próxima gestação era muitíssimo baixo.

O desenvolvimento motor tem sido aparentemente normal até a idade atual. Sustentou a cabeça com 3 meses, sentou no $6^{\circ}$ mês, engatinhou no $9^{\circ}$ mês e andou no $12^{\circ}$ mês. Falou as primeiras palavras aproximadamente com 12 meses e, atualmente, aos 23 meses, seu vocabulário consta de várias palavras. $\mathrm{O}$ desenvolvimento cognitivo é aparentemente adequado para a idade cronológica. A visão e a audição, segundo a mãe, parecem normais. O início da dentição ocorreu aos 6 meses de idade.

$\mathrm{O}$ exame físico evidenciou peso $=9.100 \mathrm{~g}$ (abaixo do percentil 2,5); estatura $=79 \mathrm{~cm}$ (abaixo do percentil 2,5); perímetro cefálico $=46 \mathrm{~cm}$ (percentil 2,5); perímetro torácico $=45 \mathrm{~cm}$. Pulso rítmico, com $82 \mathrm{bat} / \mathrm{min}$. Na ausculta cardíaca, as bulhas eram normofonéticas, e não existiam sopros. Pulmões livres. Sem visceromegalia. Coluna sem desvios patológicos. Assimetria da face e crânio. Fronte curta e assimétrica. Telecanto. Narinas estreitas com sulcos presentes nas aletas nasais (coloboma nasal). Filtro longo. Boca pequena por fusão das comissuras labiais, simulando o ato de estar assobiando (Figura 1). Presença de pregueamento cutâneo em forma de $\mathrm{H}$ abaixo do lábio inferior. Micrognatia. Língua pequena, palato arqueado e dentes com má-oclusão. Pescoço curto. Nas mãos havia flexão contratural e desvio ulnar dos dedos. Prega única de flexão palmar estava presente na mão esquerda. Nos pés havia desvio dos $5^{\circ}$ pododáctilos. Reflexos osteotendinosos com resposta adequada. Genitália com discreta hipoplasia de pequenos lábios. Audição aparentemente normal. A paciente apresentou um comportamento dócil, interagindo bem com o examinador.

\section{Caso 2}

C.E.F.C., é um lactente de 5 meses de idade, ativo e que sorri facilmente quando estimulado pelo examinador. É o produto da terceira gestação igualmente não planejada, não desejada e com assistência pré-natal completa. A mãe apresentou infecção urinária e anemia durante a gestação. Movimentos fetais se fizeram presentes a partir do $2^{\circ}$ mês de gestação. Nasceu de parto cesáreo no termo, com peso adequado para a idade gestacional. Apresentação cefálica. Hidramnios normais. Placenta e cordão umbilical normais (sic). Nascimento sem asfixia perinatal. $\mathrm{PN}=3.450 \mathrm{~g}$. Estatura ao nascer $=49 \mathrm{~cm}$. Não apresentou intercorrências perinatais. Teve alta da maternidade com a mãe. 


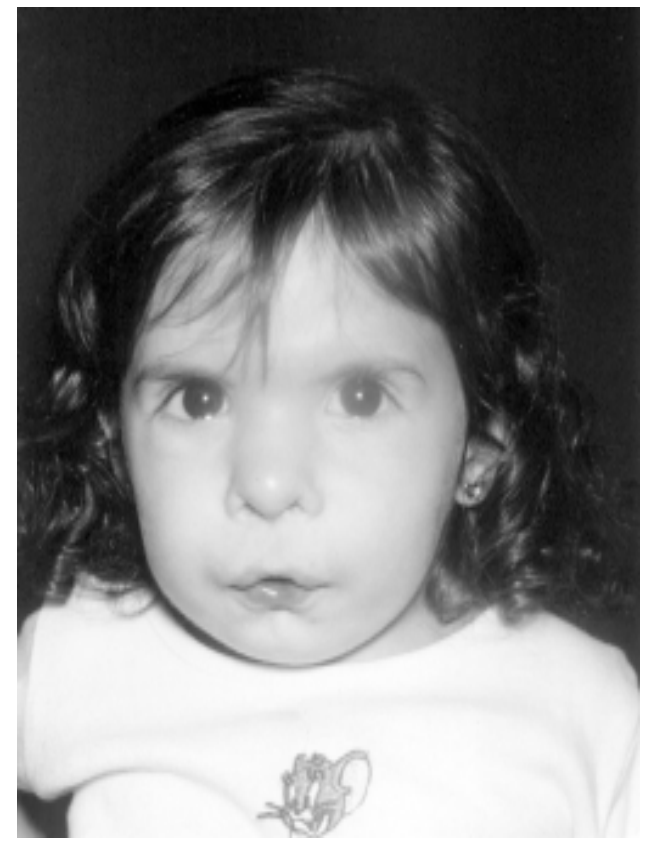

Figura 1 - Caso 1: face da propósita onde, além de telecanto, existem narinas estreitadas com sulcos nas aletas nasais, boca pequena em posição de assobio, pregueamento cutâneo baixo do lábio inferior e micrognatia

Na história patológica pregressa do paciente há referência a uma infecção urinária ocorrida no $1^{\circ}$ mês de vida e uma anemia já controlada. O desenvolvimento neuropsicomotor tem sido aparentemente normal para a idade cronológica. Sustentou a cabeça a partir do $3^{\circ}$ mês de vida.

$\mathrm{O}$ exame físico evidenciou peso $=4.570 \mathrm{~g}$ (abaixo do percentil 2,5); estatura $=58 \mathrm{~cm}$ (percentil 2,5); perimetro cefálico $=44 \mathrm{~cm}$ (percentil 50). A freqüência cardíaca era de $88 \mathrm{bat} / \mathrm{min}$. Na ausculta as bulhas eram normofonéticas e não foram detectados sopros. Pulmões livres. Fígado palpável no rebordo costal direiro.

$\mathrm{O}$ exame morfológico mostrou assimetria de face e crânio. Macrocefalia relativa. Fronte encurtada e assimétrica. Telecanto. Narinas estreitadas e chanfradura nas aletas nasais (coloboma nasal). Filtro longo. Boca pequena por fusão parcial das comissuras labiais, dando o aspecto de estar assobiando (Figura 2). Existia um pregueamento cutâneo logo abaixo do lábio inferior. Micrognatia. No exame da orofaringe foi observada uma língua pequena e um palato arqueado. O pescoço era curto. Nas extremidades havia desvio ulnar e contraturas em flexão dos dedos (camptodactilia); polegar com baixa implantação e adução, sendo cavalgado pelos outros dedos. Prega única de flexão palmar bilateral. Pé torto congênito eqüinovaro acompanhado de contraturas dos dedos dos pés (Figura 3). Bom tônus. Reflexos osteotendinosos com resposta adequada.
No exame da genitália externa não se conseguiu palpar o testículo esquerdo na bolsa escrotal ou na região inguinal ou perineal, caracterizando uma criptorquidia unilateral.

Familiares: o aspecto facial da progenitora é normal (Figura 4). O pai, faleceu com a idade de 24 anos vítima de um assalto, mas segundo a mãe, ele não apresentava alterações faciais ou das extremidades. Uma fotografia do pai avaliada em nosso Serviço atesta esta afirmação. Os pais não eram consangüíneos. Outros familiares maternos e paternos mais distantes, como avós e tios das crianças não foram por nós examinados, mas foram referidos como sendo normais.

\section{Discussão}

A SFS é reconhecidamente uma parte integrante dos distúrbios que se acompanham de contraturas múltiplas congênitas. Uma contratura congênita é definida como uma anomalia estrutural que impede a flexão e/ou extensão normal em uma determinada área corpórea. A presença de contraturas em duas ou mais áreas corporais no recémnascido costuma ser denominada de artrogripose. Entretanto, trata-se de um termo apenas descritivo, não sendo patognomônico nem diagnóstico. Antley et al. ${ }^{12}$ estabeleceram os critérios diagnósticos para a SFS. Na tentativa de classificar as artrogriposes distais, Bamshad et al. ${ }^{13}$ identificaram um total de 9 distúrbios relacionados com a SFS, sendo que nesta classificação ela recebeu o rótulo de artrogripose distal tipo $2 \mathrm{~A}$.

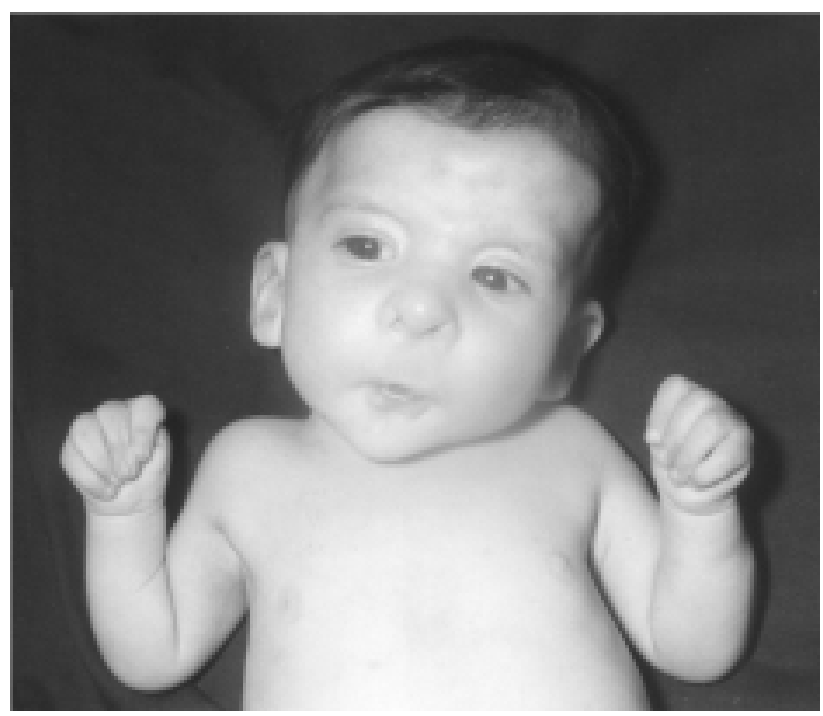

Figura 2 - Caso 2: fronte encurtada e assimétrica, telecanto, narinas estreitadas com chanfraduras nas aletas nasais, microstomia com aspecto de assobio, pregueamento cutâneo baixo do lábio inferior e flexão contratural dos dedos 


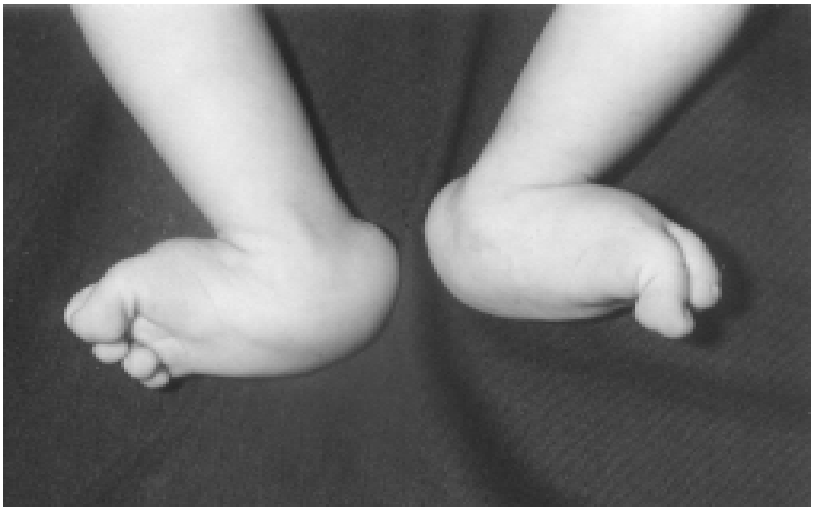

Figura 3 - Caso 2: observar pé torto congênito bilateral acompanhado de contraturas dos dedos dos pés

Curiosamente, é comum crianças com a SFS serem consideradas como apenas simples casos de artrogripose antes de receberem um diagnóstico definitivo da síndrome. Entretanto, cumpre assinalar que nem todas as crianças com artrogripose possuem a SFS. Do mesmo modo, a presença de anomalias craniofaciais sugestivas de SFS que não são acompanhadas de artrogripose constitui uma observação bastante rara e, por si só, não permitiria um diagnóstico de SFS. Toydemir et al. ${ }^{14}$ descreveram o único caso existente na literatura de uma criança com o fenótipo da face assobiadora, porém sem anomalias contraturais presentes nos membros superiores ou inferiores. O paciente era o produto de pais normais e não consangüíneos.

As anomalias craniofaciais presentes na SFS são suficientemente típicas e costumam conferir a clássica aparência de um indivíduo que estivesse assobiando. Contribuem para esta expressão facial peculiar a boca pequena com os lábios finos projetados para fora e as bochechas insufladas. Ademais, costuma haver uma microglossia e uma micrognatia associadas. O palato costuma ser muito alto. Anormalidades oculares são freqüentes. Os olhos, além de introjetados e com as fendas palpebrais inclinadas para baixo, apresentam um telecanto primário e, ocasionalmente, pode haver estrabismo ou ptose palpebral.

Crianças com a SFS freqüentemente exibem problemas de fala. Estes problemas são mais acentuados naqueles casos que se acompanham de uma hipoacusia. Como regra geral, um possível comprometimento da audição deverá ser sempre pesquisado nos casos de SFS, especialmente naqueles em que os distúrbios da fala são mais acentuados e poderiam estar sendo agravados pela hipoacusia. A disfagia é uma manifestação clínica freqüentemente relatada pelos pais e seria um dos fatores responsáveis pelos distúrbios alimentares, particularmente a regurgitação ou vômitos. Além disso, a própria microstomia dificulta a ingestão e mastigação de certos alimentos, acrescido do fato de que podem existir alterações ortodônticas concomitantes. Difi- culdade para ganhar peso, déficit de crescimento e complicações respiratórias que colocam a vida do paciente em perigo são outras intercorrências pediátricas relativamente freqüentes na SFS. As anomalias estruturais localizadas na orofaringe e nas vias aéreas superiores, comumente encontradas nestes pacientes, resultam em uma freqüente preocupação quando há necessidade de administrar uma anestesia geral, fato não incomum em vista dos vários tipos de cirurgia corretiva que geralmente se fazem necessárias. Entre as várias publicações que abordaram especificamente esta questão, ressaltamos a de Munro et al. ${ }^{15}$, dirigida a pacientes pediátricos. Muitas vezes a intubação traqueal por laringoscopia direta é impossível de ser realizada nestas crianças. Robinson ${ }^{16}$ relatou um caso de SFS acompanhado de grave obstrução das vias aéreas superiores que necessitou de traqueostomia neonatal.

Embora a maioria dos casos de SFS ocorra esporadicamente, aceita-se a existência de dois tipos de transmissão hereditária para a síndrome. Um mais freqüente, autossômico dominante, e o outro mais raro, autossômico recessivo. O conhecimento da existência de uma heterogeneidade genética nesta síndrome é muito importante para o processo de aconselhamento genético das famílias. A maior dificuldade seria após o nascimento de um primeiro caso da síndrome em uma família na qual os progenitores são normais. Esses casos poderiam ser sempre interpretados como sendo necessariamente uma mutação dominante esporádica, e a família ser informada de que o risco de recorrência numa próxima gestação seria impreterivelmente muito baixo. Foi justamente isso que aconteceu na família aqui relatada, ao procurar um serviço de aconselhamento genético após o nascimento da filha afetada pela SFS. Acreditando-se então na existência de casos de SFS com

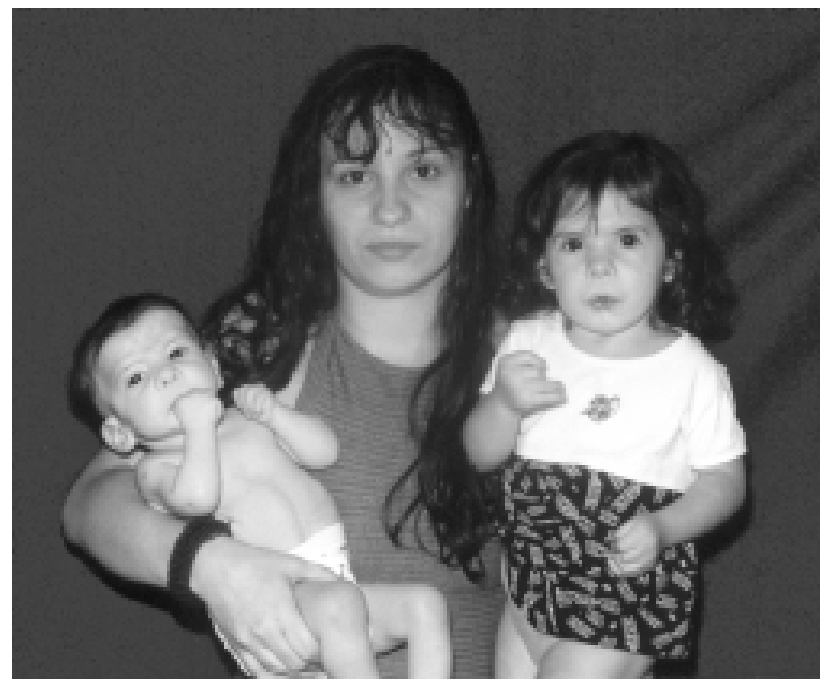

Figura 4 - Progenitora com os dois filhos afetados pela SFS. Ela não apresenta nenhuma característica fenotípica da síndrome 
herança autossômica recessiva (com risco de recorrência equivalente a $25 \%$ ), caberia apresentar a essas famílias riscos de recorrência empíricos, os quais levariam em consideração todas essas possibilidades de transmissão do gene responsável pelo distúrbio. Na família relatada por Alves e Azevedo ${ }^{7}$, os progenitores normais de duas crianças com SFS eram consangüíneos, fato considerado relevante na herança autossômica recessiva.

O relato da família por nós observada é importante para reforçar a ocorrência da forma recessiva da SFS já suspeitada por outros autores. Bekir et al. ${ }^{17}$ estão entre aqueles que descreveram dois irmãos afetados pela SFS com progenitores normais. Embora hajam explicado que a recorrência da síndrome tenha sido fruto de uma herança autossômica recessiva, eles também aventaram a remota possibilidade de existir um mosaicismo germinativo para o gene mutado em um dos progenitores.

Alterações neurológicas importantes em crianças com a SFS foram descritas recentemente na literatura por Lev et al. ${ }^{18}$ Estes autores admitiram a existência de várias síndromes distintas associando face de assobio com contraturas articulares, umas autossômicas dominantes sem envolvimento neurológico e outras autossômicas recessivas, geralmente com comprometimento neurológico em graus variáveis. Sener ${ }^{19}$ descreveu com detalhes os achados cerebrais encontrados na ressonância magnética de pacientes com SFS. Na família por nós aqui descrita, apesar de seguir um padrão de herança autossômico recessivo, não existem evidências de um comprometimento neurológico ou de déficit auditivo neurossensorial até o presente momento. Zampino et al. ${ }^{20}$ também descreveram um caso esporádico da SFS em um menino com hipertonicidade acentuada, disfagia, e atrofia cerebelar e do tronco cerebral, além de perda auditiva associada. Estes autores sugeriram que anomalias cerebrais primárias poderiam explicar várias manifestações da síndrome. Eles sugerem que uma investigação para detectar anomalias do sistema nervoso central e da audição faça parte da avaliação inicial de todo paciente suspeito de ter a SFS.

Nos últimos anos tem sido tentado o mapeamento do gene responsável pela SFS. Havendo sido comprovado que a apresentação clínica da SFS é heterogênea, resultando em subgrupos distintos de indivíduos afetados, é provável que cada um desses subgrupos seja causado por mutação em um gene específico. Até o presente momento conseguiu-se apenas o mapeamento de genes para distúrbios correlatos à SFS. Bamshad et al. ${ }^{21}$, em 1994, mapearam na região pericentromérica do cromossomo 9 um gene responsável por um desses distúrbios, mais precisamente a artrogripose tipo 1A. Esse mesmo grupo de investigadores, em $1996^{22}$, conseguiram mapear no cromossomo 11 o gene responsável pela artrogripose 2B. Uma das dificuldades existentes para o mapeamento do gene responsável pela SFS propriamente dita (artrogripose distal tipo 2A) tem sido o tamanho reduzido das famílias contendo vários indivíduos afetados pelo distúrbio. Enquanto não se identifica o gene responsável pela SFS, fica impossível fazer o diagnóstico pré-natal deste distúrbio através de análise direta pelo DNA. Entretanto, Robbins-Furman et al. ${ }^{23}$ conseguiram fazer o diagnóstico da SFS em um feto de 20 semanas, com história familiar positiva do distúrbio, através de uma avaliação ultra-sonográfica. Eles se basearam nas alterações das extremidades do feto visualizadas através da ultrasonografia.

O seguimento de crianças com a SFS requer um apoio de cuidados especiais que invariavelmente incluem um prolongado tratamento ortodôntico e ortopédico. A fisioterapia melhora a marcha, enquanto o acompanhamento fonoaudiológico alivia os problemas da fala. A correção cirúrgica da microstomia é bastante importante não só sob o ponto de vista estético, como também funcional, em relação à ingesta alimentar, tendo sido relatados bons resultados ${ }^{24}$.

\section{Referências bibliográficas}

1. Freeman EA, Sheldon JH. Cranio-carpotarsal dystrophy: undescribed congenital malformation. Arch Dis Child 1938; 13: 277-83.

2. Hall JG, Reed SD, Greene G. The distal arthrogryposes: delineation of new entities-review and nosologic discussion. Am J Med Genet 1982; 11:185-239.

3. Sedano HO. Cranio-Carpo-Tarsal dysplasia, whistling face type. In: Buyse ML, ed. Birth Defects Encyclopedia, $1^{\text {st }}$ ed. Cambridge, Massachusetts, Blackwell Scientific Publications; 1990. p.456-7.

4. Fraser FC, Pashayan H, Kadish ME. Cranio-carpo-tarsal dysplasia. Report of a case in father and son. JAMA 1970; 8:1374-6.

5. Klemp P, Hall JG. Dominant distal arthrogryposis in a Maori family with marked variability of expression. Am J Med Genet 1995;414-9.

6. Temtany S, McKusick V. Contracture deformities as a part of syndromes. Birth Defects Original Article Series 1978; 3:447-9.

7. Alves AFP, Azevedo ES. Recessive form of Freeman-Sheldon's syndrome or "whistling face”. J Med Genet 1977;14:139-41.

8. Dallapiccola B, Giannotti A, Lembo A, Sagui L. Autosomal recessive form of whistling face syndrome in sibs. Am J Med Genet 1989; 22:542-4.

9. Fitzsimmons JS, Zaldua V, Chrispin AR. Genetic heterogeneity in the Freeman-Sheldon syndrome: two adults with probable autosomal recessive inheritance. J Med Genet 1984; 21:364-8.

10. Kousseff BG, McConnachie P, Hadro TA. Autosomal recessive type of whistling face syndrome in twins. Pediatrics 1982; 69: 328-31.

11. Sanchez JM, Kaminker CP. New evidence for genetic heterogeneity of the Freeman-Sheldon syndrome. Am J Med Genet 1986; 25: 507-11.

12. Antley RM, Uga N, Burzynski NJ, Baum RS, Bixler D. Diagnostic criteria for the whistling face syndrome. Birth Defects Original Article Series 1975; 11:161-8.

13. Bamshad M, Jorde LB, Carey JC. A revised and extended classification of distal arthrogryposis. Am J Med Genet 1996; 65:277-81. 
14. Toydemir PB, Toydemir R, Bokesoy I. Whistling face phenotype without limb abnormalities. (Letter) Am J Med Genet 1999; 86: 86-7.

15. Munro HM, Butler PJ, Washington EJ. Freeman-Sheldon (whistling face syndrome). Anesthetic and airway management. Pediatric Anaesthesia 1997; 4:345-8.

16. Robinson PJ. Freeman-Sheldon syndrome: severe upper airway obstruction requiring neonatal tracheostomy. Pediatric Pulm 1997; 6:457-9.

17. Bekir N, Bayraktaroglu YC, Coskun Y, Karaaslan C. Whistling face (Freeman Sheldon) syndrome in two siblings. The Turkish J Pediatr 1994; 36:329-32.

18. Lev D, Yanoov M, Weintraub S, Lerman-Sagie T. Progressive neurological deterioration in a child with distal arthrogryposis and whistling face. J Med Genet 2000; 37: 231-3.

19. Sener RN. Whistling face syndrome. MR imaging findings in the brain. Europ Radiol 1996; 1:102-4.

20. Zampino G, Conti G, Balducci F, Moschini M, Macchiaiolo M, Mastroiacovo P. Severe form of Freeman-Sheldon syndrome associated with brain anomalies and hearing loss. Am J Med Genet 1996; 62: 293-6.

21. Bamshad M, Watkins WS, Zenger RK, Bohnsack JF, Carey J, Otterud B, et al. A gene for distal arthrogryposis type 1 maps to the pericentromeric region of chromosome 9. Am J Hum Genet 1994; 55:1153-8.
22. Krakowiak PA, Bohnsack JF, Carey JC, Bamshad M. Clinical analysis of a variant of Freeman-Sheldon syndrome (DA2B). Am J Med Genet 1998; 76:93-8.

23. Robbins-Furman P, Hecht JT, Rocklin M, Maklad N, Greenhaw G, Wilkins I. Prenatal diagnosis of Freeman-Sheldon syndrome (Whistling face). Pren Diagn 1995; 15:179-82.

24. Ohyama K, Susami T, Kato Y, Amano H, Kuroda T. FreemanSheldon syndrome. Case management from age 6 to 16 years. Cleft Palate Craniofac J 1997; 34:151-3.

\section{Endereço para correspodência:}

Dr. Gerson Carakushansky

Rua General Artigas, 104 - apto. 401 - Leblon

CEP 22450-010 - Rio de Janeiro, RJ

Fones: (21) 294.0640/ 547.6838

Fax: (21) 540.8834

E-mail: gercar@vento.com.br 